\title{
Soil texture estimation over a semi-arid area using TERRASAR-X radar data
}

\author{
M. Zribi ${ }^{1}$, F. Kotti ${ }^{1}$, Z. Lili-Chabaane ${ }^{1}$, N. Baghdadi $^{2}$ \\ ${ }^{1}$ CESBIO (CNRS/IRD/UPS/CNES), 18 av. Edouard Belin, bpi 2801, 31401 Toulouse \\ cedex 9 , France \\ ${ }^{2}$ CEMAGREF, UMR TETIS, 500 rue François Breton, 34093 Montpellier cedex 5, France
}

\begin{abstract}
In this paper, it is proposed to use TERRASAR-X data for analysis and estimation of soil surface texture. Our study is based on experimental campaigns carried out over a semi-arid area in North Africa. Simultaneously to TERRASAR-X radar acquisitions, ground measurements (texture, soil moisture and roughness) were made on different test fields. A strong correlation is observed between soil texture and a processed signal from two radar images, the first acquired just after a rain event and the second corresponding to dry soil conditions, acquired three weeks later. An empirical relationship is proposed for the retrieval from radar signals of clay content percent. Soil texture mapping is proposed over the study site, which includes bare soils and olive groves.
\end{abstract}

Keywords: Radar, TERRASAR-X, soil texture, soil clay, modelling, mapping 


\section{Introduction}

The implementation of sustainable agricultural and environmental management requires an improved understanding of the soil, at increasingly finer scales. Conventional soil sampling and laboratory analyses cannot efficiently provide this information, because they are slow and expensive. Different methodologies have been proposed over the last decades, for the estimation of soil textures using specific multi- and hyper-spectral sensors, allowing the rapid and relatively inexpensive measurement of soil properties (eg. [1-3]). Remote sensing can provide soil information over large geographical areas, but has the drawback of detecting, in most cases, only the top few millimetres at the surface of the soil profile.

Active remote sensing has shown considerable potential for the characterisation of different soil parameters, moisture and roughness in particular. In recent years, some studies have illustrated the potential of SAR measurements and very high resolution data for the retrieval of soil texture. [4-5] have already observed TerraSAR-X SAR data variations due to soil texture within agricultural plots. They demonstrated that the SAR signal is $3 \mathrm{~dB}$ weaker for a soil composition with more clay (32\% clay, $64.5 \%$ silt and $3.5 \%$ sand) than for a soil with less clay (17\% clay, $79 \%$ silt and $4 \%$ sand). In a recent study, Aubert et al., [6] show a high correlation between the radar signal and the hydric evolution of soil crust variations. Soils with slaking crust have a greater hydric inertia than soil without crust. Consequently, following rainfall or dry events, soil moisture in the upper centimeters may differ between the two soil structures, resulting in variations in the TerraSAR-X signal within the field. Thus, it is sometimes possible to track surface degradation due to the slaking process using the TerraSAR-X sensor. Our objective in the present study is to estimate the soil clay percent using TERRASAR-X radar data over a semi-arid region situated in North Africa.

\section{Data base}

\section{A. Study site}


The study area is located on the Kairouan plain [7], situated in central Tunisia $\left(9^{\circ} 23^{\prime}\right.$ -

$10^{\circ} 17^{\prime} \mathrm{E}, 35^{\circ} 1^{\prime}-35^{\circ} 55^{\prime} \mathrm{N}$ ) as shown in Figure 1 . The climate in this region is semi-arid, with an average annual rainfall of approximately $300 \mathrm{~mm}$ per year, characterised by a rainy season lasting from October to May, with the two rainiest months being October and March. As is generally the case in semi-arid areas, the rainfall patterns in this area are highly variable in time and space. The mean temperature in Kairouan City is $19.2^{\circ} \mathrm{C}$ (minimum of $10.7{ }^{\circ} \mathrm{C}$ in January and maximum of $28.6{ }^{\circ} \mathrm{C}$ in August). The landscape is mainly flat, and the vegetation in this area is dominated by agriculture (cereals, olive groves, fruit trees and market gardens).

\section{B. Satellite database}

Three TerraSAR-X images $(\sim 9.65 \mathrm{GHz})$ were acquired at high incidence angles $\left(35^{\circ}\right)$ in the horizontal polarisation. The images were taken with a horizontally polarized beam, with a ground pixel spacing of $1 \mathrm{~m}$.

Radiometric calibration of the TerraSAR-X signals was carried out [8]. All of the radar images were then geo-referenced using optically geo-referenced images.

\section{Ground measurements over the test fields}

The field campaigns presented in this study were carried out on the $8^{\text {th }}, 12^{\text {th }}, 19^{\text {th }}$ and $30^{\text {th }}$ of March, 2010. The first of these dates (March $8^{\text {th }}$ ) was one day after a period of heavy rain. The soil was wet on the first day, following which its surface progressively dried up due to the influence of strong solar radiation and wind. There was no further precipitation during the 21 day measurement period.

Simultaneously with the radar measurements, ground truth measurements of soil roughness, moisture content, bulk density and texture were carried out on several test fields. A larger number of field plots were sampled during the full set of campaigns.

- Soil texture 
Soil texture measurements were carried out over thirty test fields. For each test field, several soil samples were made and the measurements were processed in the laboratory. These indicated clay percents ranging between 12 and 53\%. The sand percents lay in the range between $21 \%$ and $71 \%$, with the highest values being observed in non-irrigated olive groves, which are particularly well adapted to sandy soil.

\section{- Soil roughness}

Soil roughness measurements were made using a pin profiler (with a total length of $1 \mathrm{~m}$ and a resolution of $2 \mathrm{~cm}$ ). In order to improve the accuracy of the roughness computations, approximately 10 profiles were recorded for each field. As shown by Lievens et al., (2009), [9], the limited resolution defined by the pin spacing, together with the short length of the profiler, would lead to some errors in our statistical computations. As the surface height profile is considered to be ergodic and stationary, we can compute the correlation function for each profile [10], and derive two statistical parameters: the rms surface height (vertical scale of roughness), and the correlation length $(l)$, which represents the horizontal scale over which similar roughness conditions are detected. The $r m s$ height values varied between $0.6 \mathrm{~cm}$ and $1.5 \mathrm{~cm}$, and the correlation length between 3 and $8 \mathrm{~cm}$. For both parameters, the higher values corresponded to recently ploughed fields.

\section{- Soil moisture}

Gravimetric soil moisture samples were collected as a function of the agricultural plot size: about 10 to 20 localized samples were taken per test field, at depth in the range $0-5 \mathrm{~cm}$. The gravimetric soil moisture content was calculated by drying the samples at $105^{\circ} \mathrm{C}$ for $24 \mathrm{~h}$. The volumetric soil moisture $\left(\mathrm{M}_{\mathrm{v}}\right)$ was then obtained by multiplying the gravimetric soil moisture by the bulk density. Bulk density measurements were made for each plot site, using samples taken with Kopecky rings. Table1 illustrates the mean value of $0-5 \mathrm{~cm}$ soil surface volumetric moisture over the test fields, for each campaign day. We observe a mean decreasing of $16.65 \%$ between the $8^{\text {th }}$ and $30^{\text {th }}$ of March.

\section{- Land use mapping}


Land use classification is based on a decision tree as detailed in [7], using two types of satellite data: four SPOT images, and SRTM data. We established eight classes of land use: non-irrigated olive groves, irrigated olive groves, irrigated winter vegetables, irrigated summer vegetables, bare soils, urban areas, mountainous areas, water cover and areas of coastal salt flats (“sebkhas"). Validation of these remotely sensed classifications, based on ground verification over more than 100 fields with different types of land uses, reveals an accuracy of around $94 \%$.

\section{Analysis of the relationship between soil texture and radar signal}

\section{A. Analysis of TERRASAR-X data behaviour}

The Integral Equation Model 'IEM' backscattering model [11] is used for radar signal simulations. It has as input roughness, moisture and texture parameters. For roughness description, we consider the rms height, the correlation length and an exponential height correlation function. Figure 2 provides a comparison between radar data and backscattering simulations. Bar errors correspond to the effect of roughness input variation on simulations over one test field. In general, we observe an over-estimation in the backscattering simulations, with respect to the real radar data. This over-estimation could be explained by various factors, including: the roughness description [10], instrumental errors [9-10], and finally the soil moisture estimation. In the case of soil moisture, it is very difficult to obtain accurate data corresponding to the equivalent depth from which the radar signal is scattered. In the present study, we consider the first $5 \mathrm{~cm}$ of the soil in our ground measurements. However, from [12], the analytical penetration depth of radar wavelength can be described by:

$$
\delta_{p} \approx \frac{\lambda \sqrt{\varepsilon^{\prime}}}{2 \pi \varepsilon}
$$

which leads to a depth in X-band ranging between approximately 12 and $2 \mathrm{~mm}$, for volumetric soil moisture measurements in the range between 9 and $30 \%$. 
This backscattering behaviour is confirmed in Figure 3, showing the temporal variation of the radar signals for four different test fields. For all test fields, we observed nearly stable radar signal between the $19^{\text {th }}$ and $30^{\text {th }}$ of March. This result is with the decreasing of soil moisture measured at depth of $0-5 \mathrm{~cm}$, which ranged from approximately $15 \%$ down to $9 \%$ between these two dates. This apparent discrepancy could be explained mainly by the fact that, in the first millimetres of soil, which have the greatest influence on the X-band radar signals, there was a priori no variation in soil moisture between these two dates, as a consequence of the strong level of evaporation on the studied site. This result illustrates some limitations of Xband data for the estimation of soil moisture under such semi-arid climate conditions. In this context, we analyse the potential of TERRASAR-X data for the estimation of soil texture, as described in the following section. The main idea behind this analysis is to exploit differences in the rate at which the first millimetres of soil dry out, as a function of the percent of clay in the soil composition.

\section{B. Developed approach}

The proposed approach is based on change detection analysis. We analysed the difference between radar signals measured on the $8^{\text {th }}$ and $30^{\text {th }}$ of March, the first of these dates being just one day after a strong rainfall event $(\mathrm{P}=40 \mathrm{~mm})$, and the second date being three weeks later, with no rainfall events occurring between these two dates. We considered two types of test field: bare soils and non-irrigated olive groves. In both cases, the difference is considered as a function of soil moisture variations only. For all test fields, we verified that there was no temporal variation in roughness, and it was confirmed that no new tillage had been carried out between the two studied dates.

In the case of the olive groves, the trees are sparsely distributed, with the vegetation cover corresponding to approximately $5 \%$ of the soil surface area. In order to remove the influence of the vegetation, and to consider bare soil measurements only, we used a high-resolution 
(2.5m) optical image to identify, and then eliminate the contribution of each of the olive trees. A classification system was then applied to the images, to eliminate the tree-covered zones, thus conserving the bare soil only for further analysis, as illustrated by the example shown in Figure 4, corresponding to two test fields. We included approximately two additional pixels around the classified tree areas, in order to take the influence of the radar incidence angle into account.

We considered two sets of fields, the first of which had fifteen fields and was used for the development of our methodology, and the second of which had twelve fields and was used for its validation. For both sets, approximately the same range of clay content was assumed.

Figure 5 illustrates the relationship between processed radar signals and the clay percent in the soil, for different test fields:

$$
\Delta \sigma_{0}=f(\text { clay })
$$

From ground measurements, the clay percent ranged between $12 \%$ and $53 \%$. It can be seen that the processed backscattered radar signals have a clear dependence on the clay content $(\%)$ of the soil, with a high correlation coefficient, $\mathrm{R}^{2}$, of approximately 0.6 . The significance of the correlation between clay content and the backscattered radar signals was tested using Fisher's F test, with a significance defined as $\alpha=0.05$. We retrieved a p-value equal to 0.35. This relationship arises from the dependence of the radar signals on soil moisture content variations. An increase in the clay percent leads to higher moisture values one day after the first rainfall, and therefore to a stronger change in moisture in the first millimetres than in the case of a low clay percent. This strong difference in soil moisture, due to large differences in clay content, certainly led to strong variations in backscattered radar signal levels, between the two observation dates.

In order to validate the theoretical robustness of the behaviour observed in figure 5, we ran backscattering coefficient simulations with the IEM model, using as inputs moisture and 
texture measurements, together with various roughness values taken within the domain of validity of the IEM $(\mathrm{s}=0.3 \mathrm{~cm}, \mathrm{~s}=0.5 \mathrm{~cm}, \mathrm{~s}=0.7 \mathrm{~cm}$ and $\mathrm{l}=6 \mathrm{~cm})$. Figure 6 plots the resulting difference between the simulated signals produced by wet and dry soils, as a function of clay content. Firstly, it can be seen that the soil roughness has practically no effect on the relationship between the simulated signals and the clay content, as suggested by our analysis. Secondly, it can be observed that we retrieve the same type of relationship as that found experimentally (figure 5).

\section{Validation of our methodology}

Validation of our soil texture retrieval algorithm was based on comparisons between groundtruth estimations of clay percent and measurements derived from TERRASAR-X observations using the inversion model:

$$
\text { Clay }(\%)=4.35 \quad \exp \left(\frac{\Delta \sigma_{0}}{1.81}\right)
$$

As shown in Figure 6, the resulting RMS error is equal to $12 \%$ (in terms of clay percent), corresponding to $120 \mathrm{~g} / \mathrm{kg}$. This result is approximately in the range of errors of estimations derived from other remote sensing techniques such as hyper-spectral remote sensing [2-3].

\section{Soil texture mapping}

Following the process described above, it was possible to apply our validated model to TERRASAR-X images. On the basis of a land-use map, we took only bare soil fields and olive groves into account. In the case of the olive groves, we removed the trees from the radar images, using SPOT high resolution $(2.5 \mathrm{~m})$ images. In order to eliminate the effects of local terrain heterogeneities and speckle in the radar signals, the soil texture was estimated over cells defined by 50 x 50 pixel areas, corresponding to 50 x 50 m cells. Figure 7 shows the resulting soil texture map over the studied area. As confirmed by ground measurements, a generally lower percent of clay is found in the soil of olive groves.

\section{Conclusions}


This paper proposes a methodology which can be successfully applied to the mapping of soil texture, using TERRASAR-X radar data. Our approach is based on the fact that, after a rainfall event, the variation moisture content of the soil surface depends on the soil's texture. Our methodology is based on the detection and analysis of change, under different conditions:

1) No change in roughness or vegetation cover: in this case, the period between two successive radar images should be short.

2) Soil texture estimations are derived from processed radar signals, and then averaged over cells with 50 x 50 sample spacing.

3) The soil texture is retrieved by inverting the relationship between the processed signals and the soil clay percent.

A relationship has been established between ground-truth clay measurements and the processed radar images, with a correlation coefficient, $\mathrm{R}^{2}$ of approximately 0.6. This relationship is directly related to the difference in soil moisture variations between soils with different clay percentages, and the influence of this difference on radar signal variations. The algorithm was validated using ground truth observations, with an rms error equal to $12 \%$ (equivalent to $120 \mathrm{~g} / \mathrm{kg}$ ). The soil texture was then mapped from radar images. Optimum use of this approach could be made in autumn, at the beginning of the rainy season: during this period, following the dry season, the highest proportion of bare soils with limited vegetation can be identified.

In the context of limitation of hyper-spectral remote sensing data, and the independence of active remote sensing of meteorological conditions, X-band high resolution radar data (TERRASAR-X, COSMO-Skymed, ...) could provide a high contribution for soil texture estimation. 


\section{Acknowledgments}

This study was funded by two programs: RESAMED (French MISTRAL Program), the WASSERMED European project, and also by the French 'Institut de Recherche pour le Développement'. The authors wish to thank the DLR and ISIS programs for kindly providing our team with TERRASAR-X SAR data and SPOT images. The TERRASAR-X images were obtained under proposal HYD0007. We would also wish to thank all of the technical teams of the IRD, IGC and INAT for their strong collaboration and support in implementing the ground-truth measurements. 


\section{References}

[1] T. Selige, J. Böhner, U. Schmidhalter, "High resolution topsoil mapping using hyperspectral image and field data in multivariate regression modeling procedures", Geoderma, 136, pp. 235-244, 2006.

[2] P. Lagacherie, F. Baret, J. B. Feret, J. M. Netto, J. M. Robbez-Masson, "Estimation of soil clay and calcium carbonate using laboratory, field and airborne hyperspectral measurements", Remote Sens. Environ, Vol. 112, 3, pp.825-835, 2008

[3] C. Gomez, P. Lagacherie, G. Coulouma, "Continuum removal versus PLSR method for clay and calcium carbonate content estimation from laboratory and airborne hyperspectral measurements", Geoderma, 148, pp.141-148, 2008.

[4] N. Baghdadi, M. Zribi, C. Loumagne, P. Ansart, T. Paris Anguela, "Analysis of TerraSARX data and their sensitivity to soil surface parameters", Remote Sens. Environ, Vol. 112, 12, pp. 4370-4379, 2008.

[5] T. Paris Anguela, M. Zribi, N. Baghdadi, and C. Loumagne, "Analysis of local variation of soil surface parameters with TerraSAR-X radar data over bare agricultural fields", IEEE Trans. Geosci. Remote Sens., 48(2), pp. 874-881, 2010.

[6] M. Aubert, N. Baghdadi, M. Zribi, A. Douaoui, C. Loumagne, F. Baup M. El Hajj, S. Garrigues, 2011. Analysis of TerraSAR-X data sensitivity to bare soil moisture, roughness, composition and soil crust, Remote Sens. Environ, in press.

[7] M. Zribi, A. Chahbi, Z. Lili, B. Duchemin, N. Baghdadi, A. Chehbouni, "Multi-scale estimation of surface moisture over pluvial and irrigated fields in a semi-arid region using ASAR/ENVISAT radar data”, Hydrol. Earth Syst. Sci, 15, pp. 345-358, 2011. 
[8] T. Fritz, "TerraSAR-X Ground Segment Level 1b Product Format Specification (10.12.2007), Doc.: TX-GS-DD-3307, Issue, 1.3, 257 pages, http://www.dlr.de/tsx/documentation/TX-GS-DD-3307_Level-1b-Product-Format, Specification_1.3.pdf”, 2007

[9] H. Lievens, H. Vernieuwe, J. Álvarez-Mozos, B. De Baets and N. E. Verhoest, Error in Radar-Derived Soil Moisture due to Roughness Parameterization: An Analysis Based on Synthetical Surface Profiles, Sensors, 9(2), pp. 1067-1093; 2009.

[10] N. E. C. Verhoest, H. Lievens, W. Wagner, J. Alvarez-Mozos, M. S. Moran, and F. Mattia, "On the soil roughness parameterization problem in soil moisture retrieval of bare surfaces from Synthetic Aperture Radar," Sensors, vol. 8, no. 7, pp. 4213-4248, 2008 .

[11] A. K. Fung, Z. Li, and K. S. Chen, "Backscattering from a randomly rough dielectric surface”, IEEE Trans. Geosci. Remote Sens., 30(2), pp. 356-369, 1992

[12] F. T. Ulaby, R. K. Moore, \& A. K. Fung, "Microwave remote sensing: active and passive. From theory to applications”, Vol. 3. Boston, London: Artech House, 1098 pp, 1986. 


\section{Figures and Tables}

Table 1: Ground measurements description

Figure 1: Localisation of the Chebika site, situated in Tunisia

Figure 2: Inter-comparison between TERRASAR-X measurements and backscattered signal simulations with the IEM model, over various test fields

Figure 3: Measured radar signals as a function of time, over four different test fields. The three points in each plot correspond to the mean radar signal observed over the test fields, on three different dates $\left(8^{\text {th }}, 19^{\text {th }}\right.$ and $30^{\text {th }}$ of March).

Figure 4: Classification of two olive groves: inside each olive field, two classes of coverage can be identified: olive trees in blue and bare soil in yellow.

Figure 5: Observed relationship between clay percent and processed radar signals, over different test fields.

Figure 6: IEM simulations of the difference between the wet and dry soil backscattering coefficients, as a function of clay content, in the $\mathrm{X}$ band $(9.65 \mathrm{GHz})$ with $\mathrm{HH}$ polarisation, for three surface roughness values.

Figure 7: Inter-comparison between ground clay measurements and estimated values, based on the proposed empirical model

Figure 8: Illustration of soil clay percent mapping over the studied site 


\begin{tabular}{|l|c|l|}
\hline Date & $\begin{array}{l}\text { Mean 0-5 cm soil moisture } \\
(\%)\end{array}$ & Roughness measurements \\
\hline 08 March, 2010 & 26.15 & $0.6 \mathrm{~cm}<s<1.5 \mathrm{~cm}$ \\
& & $3 \mathrm{~cm}<l<8 \mathrm{~cm}$ \\
\hline 19 March, 2010 & 15.22 & - \\
\hline 30 March, 2010 & 9.5 & - \\
\hline
\end{tabular}

Table1: Ground measurements description 


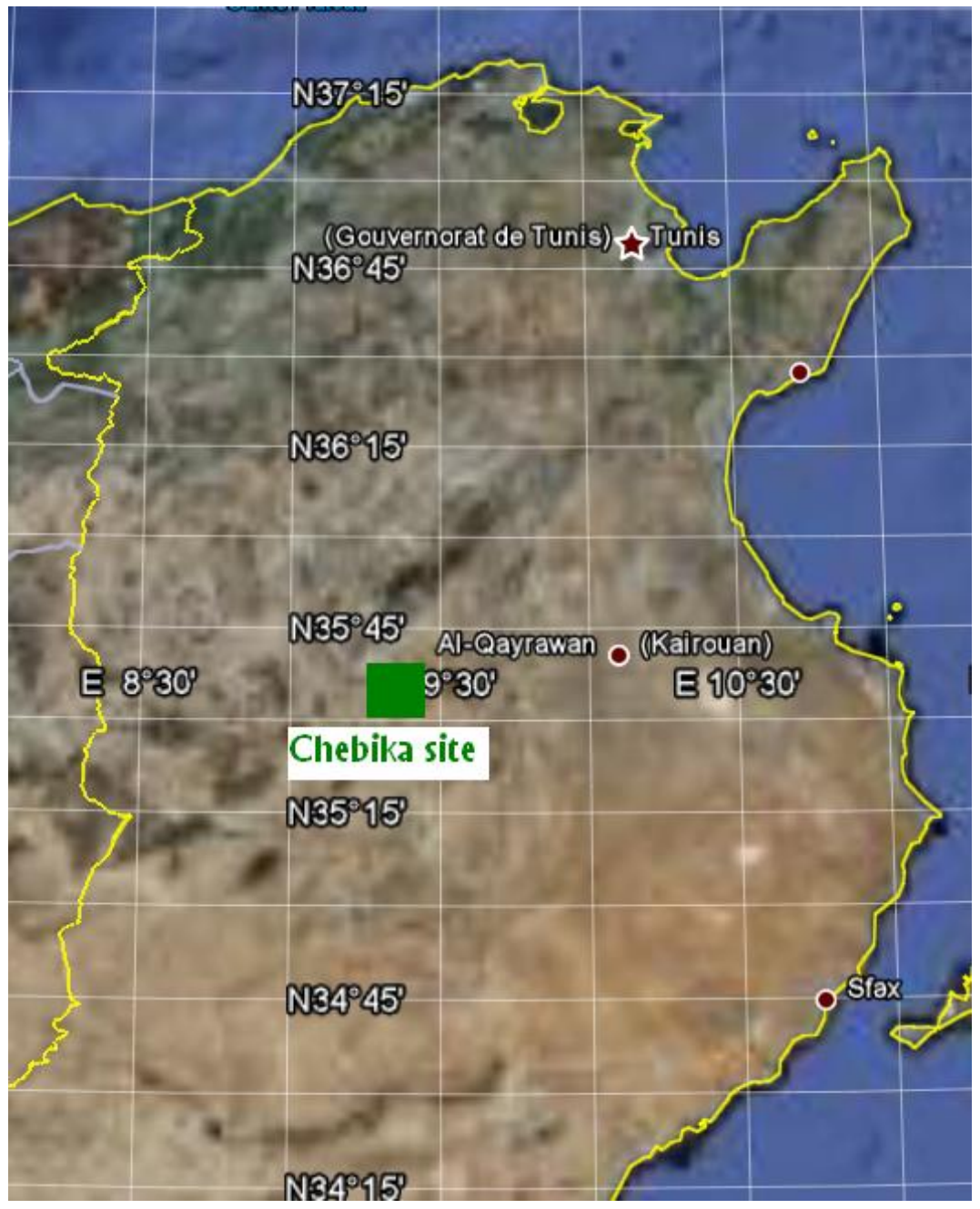

Figure 1: Localisation of the Chebika site, situated in Tunisia 


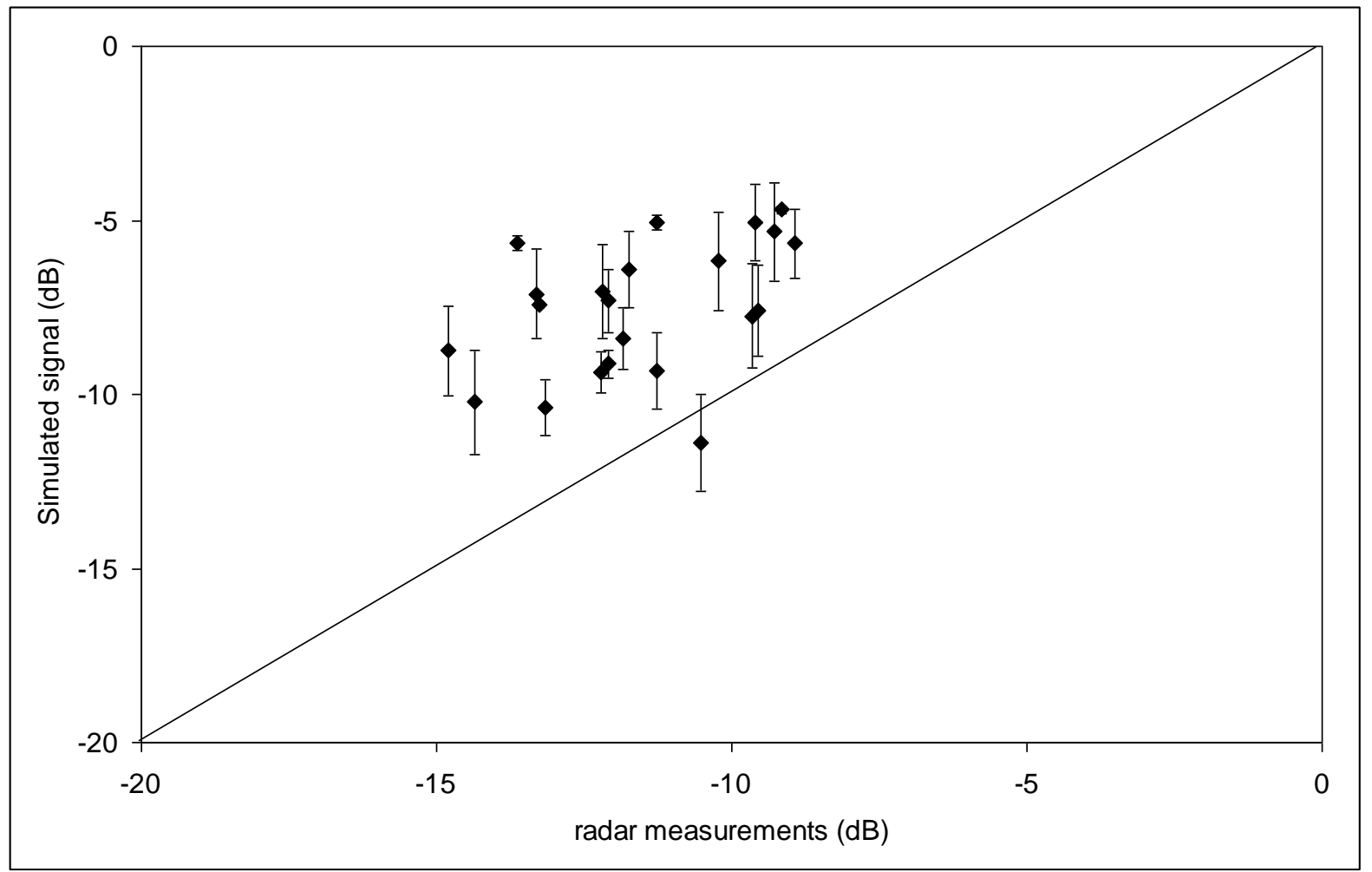

Figure 2: Inter-comparison between TERRASAR-X measurements and backscattered signal simulations with the IEM model, over various test fields 


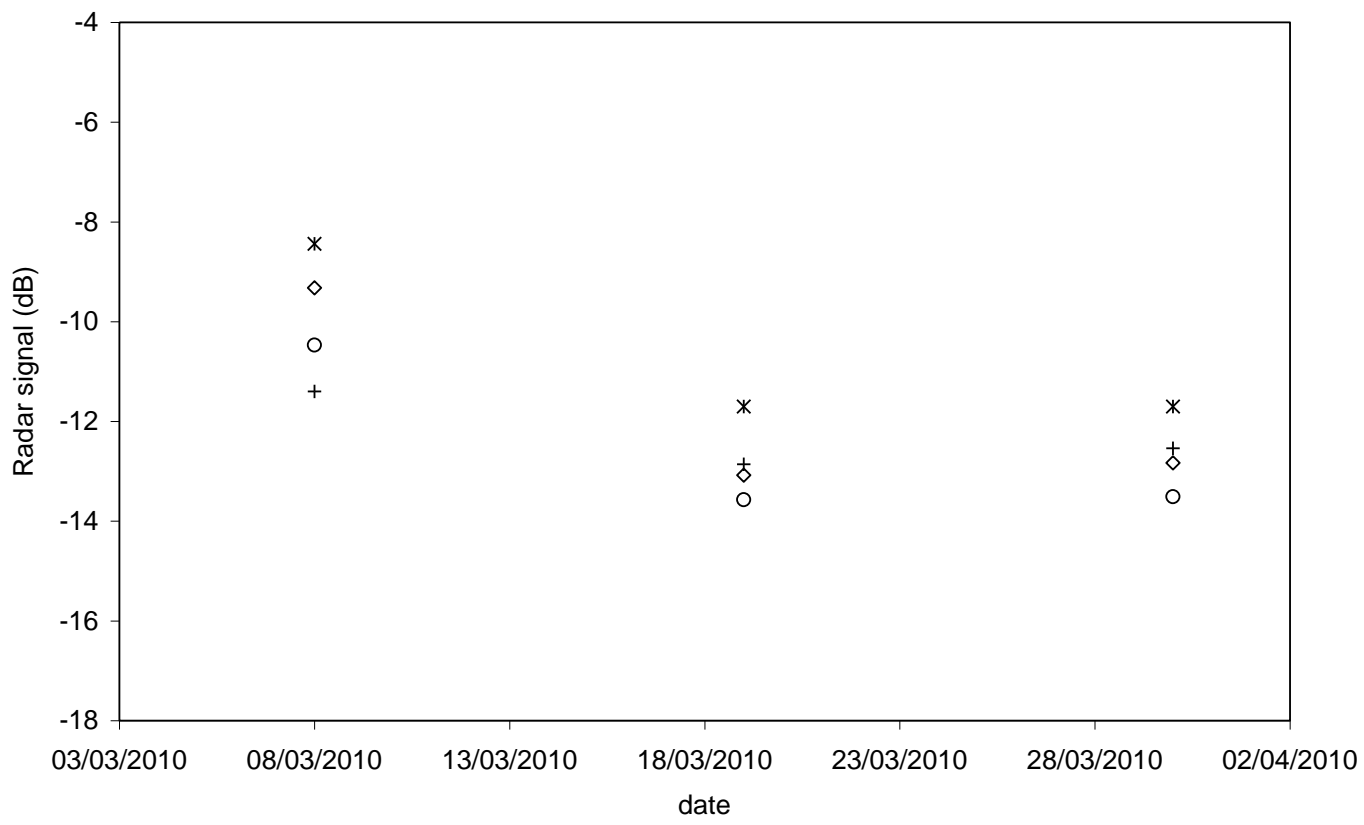

Figure 3: Measured radar signals as a function of time, over four different test fields. The points correspond to the mean radar signal observed over the test fields, on three different dates $\left(8^{\text {th }}, 19^{\text {th }}\right.$ and $30^{\text {th }}$ of March). 

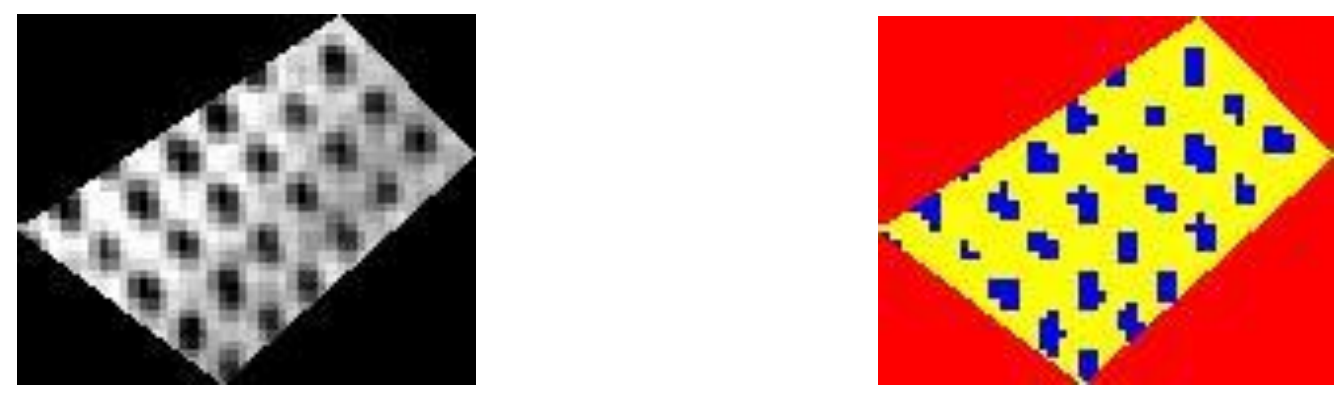

(a)
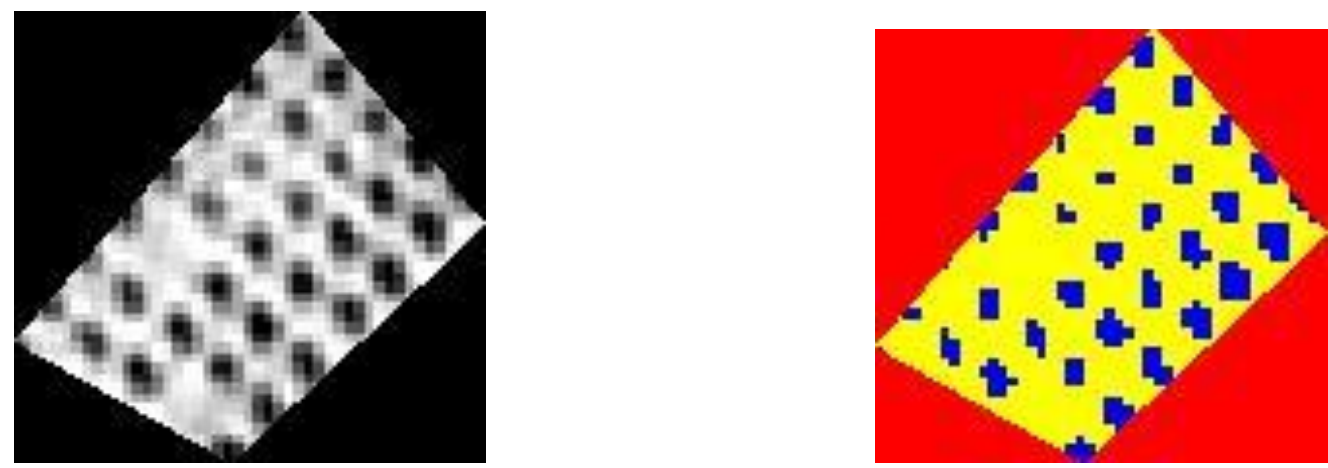

(b)

Figure 4: Classification of two olive groves: inside each olive field, two classes of coverage can be identified: olive trees in blue and bare soil in yellow. 


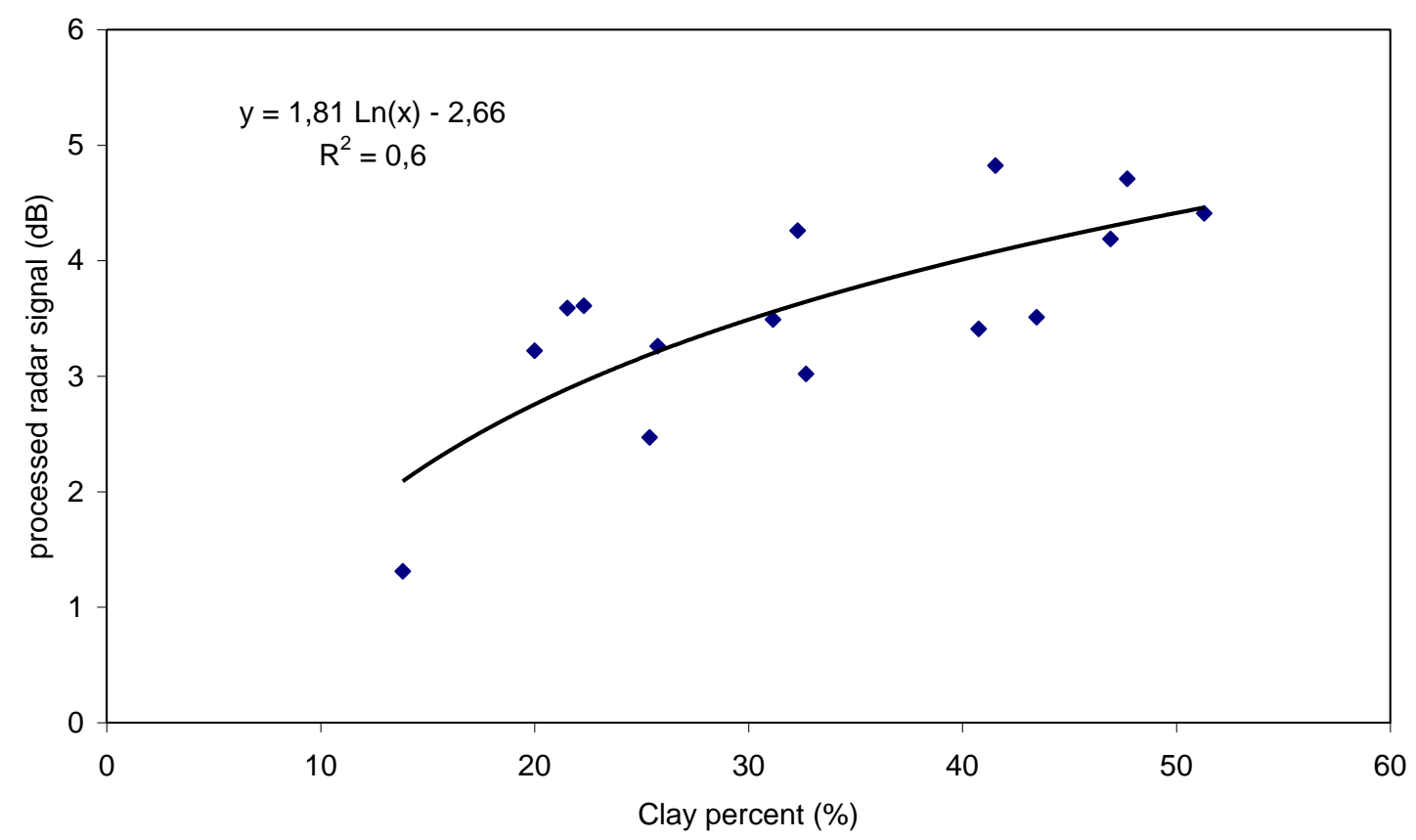

Figure 5: Observed relationship between clay percent and processed radar signals, over different test fields. 


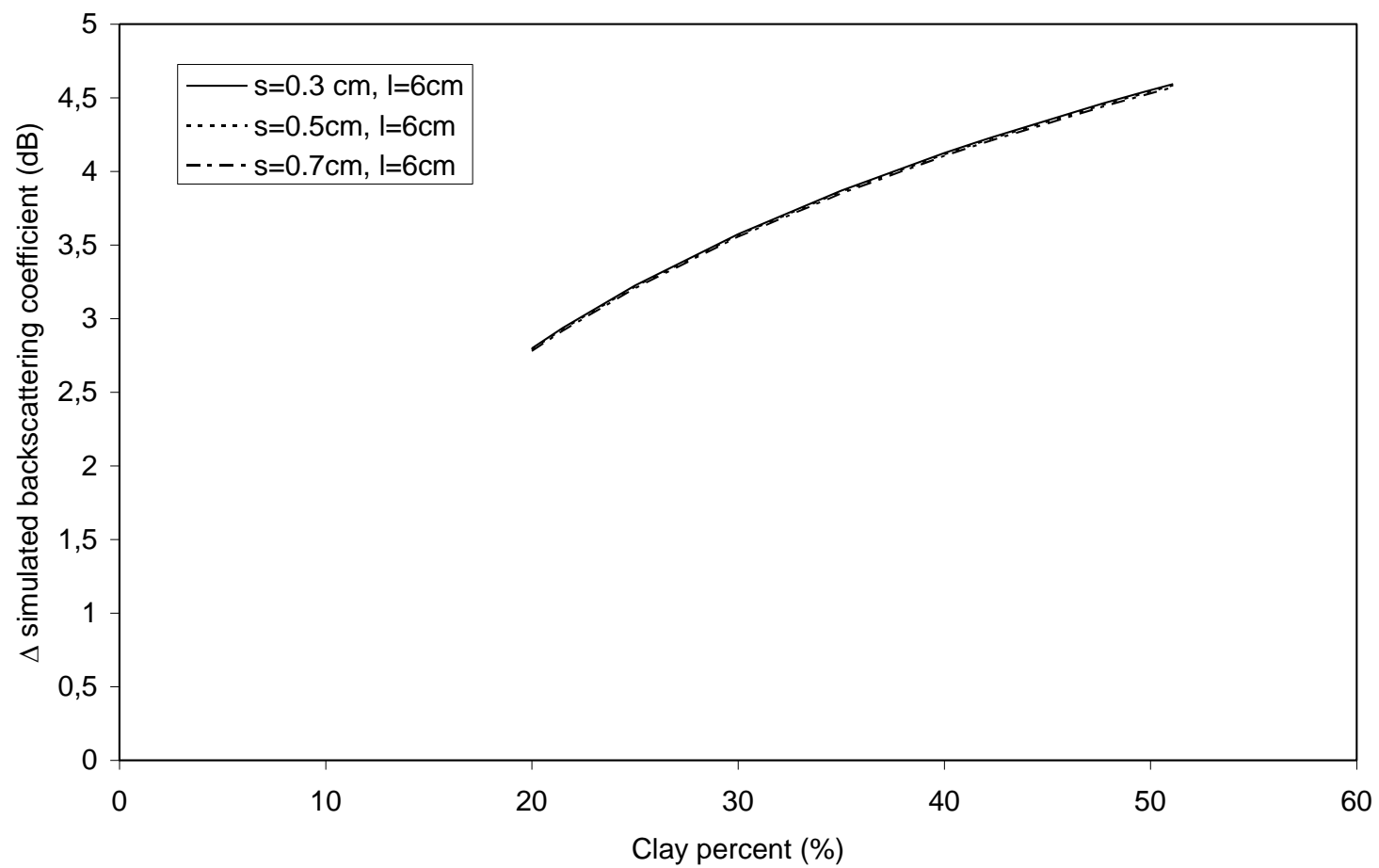

Figure 6 : Illustration of IEM simulations of backscattering coefficient difference between wet and dry soils for three surface roughness, function of clay percent, in X band $(9.65 \mathrm{GHz}), \mathrm{HH}$ polarisation. 


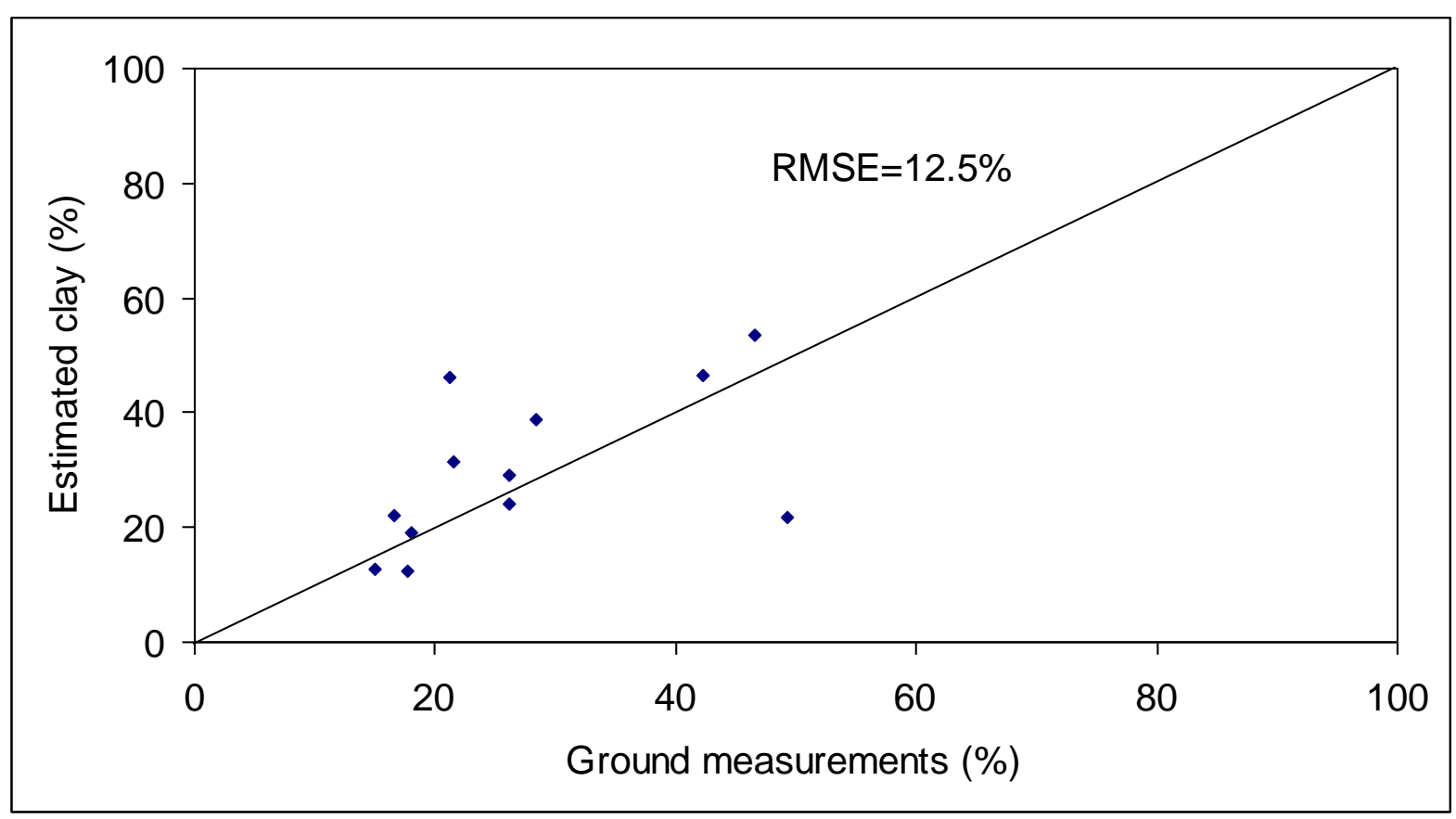

Figure 7: Inter-comparison between ground clay measurements and estimated values, based on the proposed empirical model 


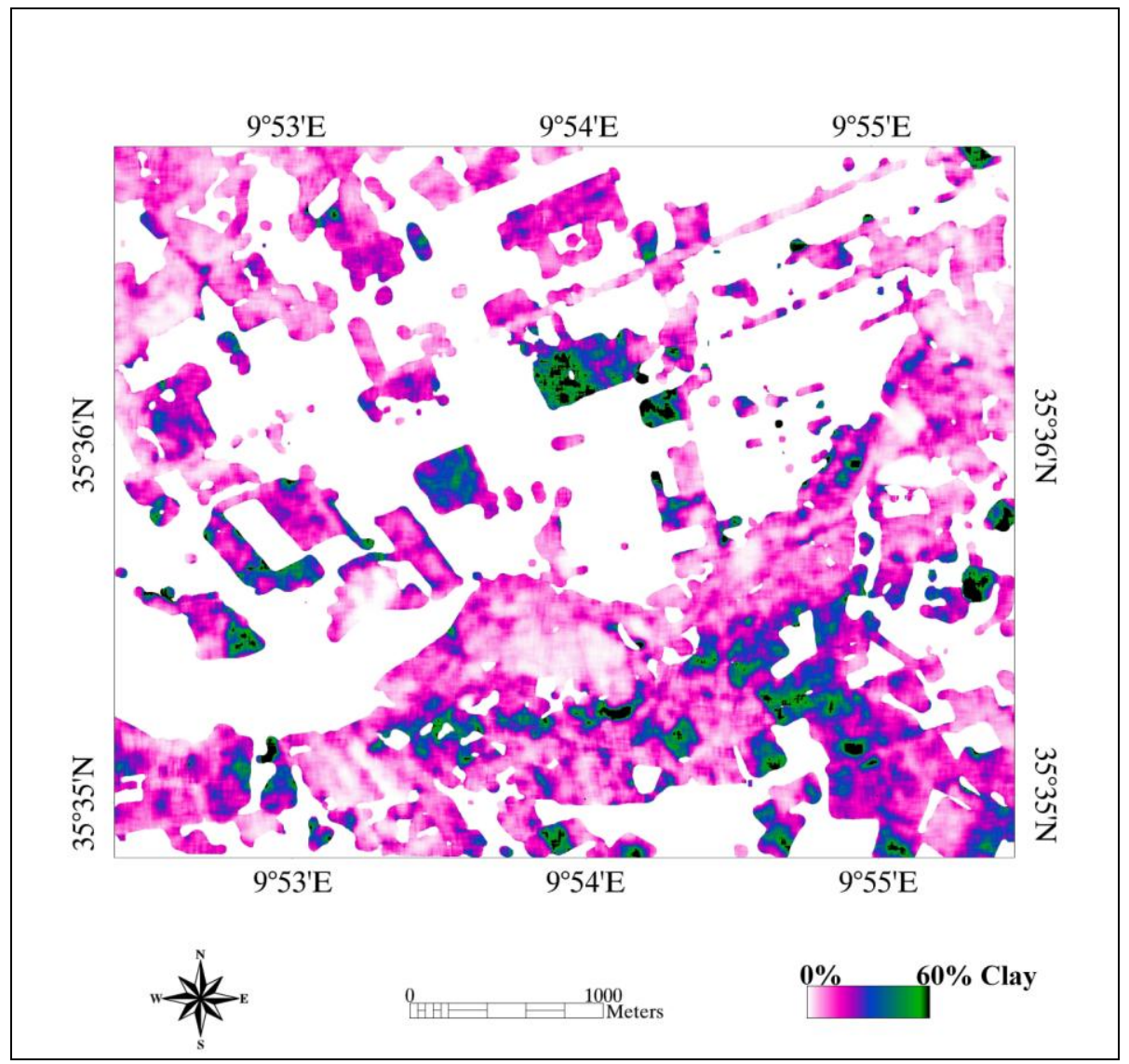

Figure 8: Illustration of soil clay percent mapping over the studied site 